\title{
Statistical investigation of extraction parameters of keratin from chicken feather using Design-Expert
}

\author{
Nuruldiyanah Binti Kamarudin ${ }^{1} \cdot$ Swati Sharma $^{1} \cdot$ Arun Gupta $^{1} \cdot$ Chua Gek Kee $^{1}$. \\ Syed Mohd Saufi Bin Tuan Chik ${ }^{1} \cdot$ Ritu Gupta $^{2}$
}

Received: 2 October 2016/Accepted: 6 February 2017/Published online: 1 June 2017

(C) Springer-Verlag Berlin Heidelberg 2017

\begin{abstract}
Uncontrolled disposal of feathers from the poultry industry and slaughterhouses is environmentally undesirable. The feathers are composed of approximately $90 \%$ of keratin which is an important ingredient of cosmetics, shampoos and hair treatment creams. This study aimed to determine the optimum conditions for the extraction of keratin from chicken feathers. The extraction of keratin using various reducing agents was studied using statistical experimental design. In the extraction process, $\mathrm{pH}$, temperature, ratio of reducing agents, mass of chicken feathers and incubation time were analyzed. The keratin in the total extracted protein was purified by size exclusion chromatography, sodium dodecyl sulfate polyacrylamide gel electrophoresis (SDS-PAGE) and further characterized using amino acids profile analysis. The surface morphology and chemical composition were studied by scanning electron microscopy (SEM) and Fourier transform infrared spectroscopy (FTIR) analysis. Sodium sulfide $\left(\mathrm{Na}_{2} \mathrm{~S}\right)$ yielded $84.5 \%$ of keratin as compared to sodium hydroxide (43.8), urea mixture (50.6), mixture of sodium dodecyl sulfate (SDS) and sodium bisulfite (18.3) and a mixture of $\mathrm{Na}_{2} \mathrm{~S}$ and sodium hydroxide (41.5\%) under optimized
\end{abstract}

Nuruldiyanah Binti Kamarudin and Swati Sharma have equal contribution in this work.

Arun Gupta

arungupta10@gmail.com

1 Faculty of Chemical Engineering and Natural Resources, Universiti Malaysia Pahang, Lebuhraya Tun Razak, 26300 Gambang, Kuantan, Pahang Darul Makmur, Malaysia

2 Faculty of Computer Systems and Software Engineering, Universiti Malaysia Pahang, Lebuhraya Tun Razak, Gambang, 26300 Kuantan, Pahang Darul Makmur, Malaysia conditions. The optimum yield of keratin was achieved at $80.9^{\circ} \mathrm{C}$ in $9.5 \mathrm{~h}$ with $0.05 \mathrm{M}$ sodium sulfide using response surface methodology (RSM). Among the five parameters screened, $\mathrm{pH}$ was found not to be significant because the $p$ value was greater than 0.05 .

Keywords Chicken feathers - Keratin protein · Reducing agents $\cdot$ Protein characterization $\cdot$ Optimization

\section{Introduction}

Feathers are available in bulk quantity as waste biomass from the poultry industry. These are always defined as "waste" which is especially difficult to dispose or recycle. For disposal of this waste biomass, burning and burying are the most common methods which create serious environmental problems. Inside the landfill, the feathers decompose very slowly and also require a large area, while burning the feathers causes air pollution; thus, it is necessary to explore alternative solutions. Various reports are available in literature to determine the physico-chemical structures and industrial applications of chicken feathers.

As reported previously, feathers comprise $\sim 90 \%$ of keratin protein in waste biomass (Gessesse et al. 2003; Grazziotin et al. 2006; Fakhfakh-Zouari et al. 2010; Saucedo-Rivalcoba et al. 2011). The two most abundant forms of keratins are called $\alpha$-keratins and $\beta$-keratins (Sharma and Gupta 2016; Barone et al. 2006). The $\alpha$-keratins occur in mammals, while $\beta$-keratins are abundant in birds and reptiles. The $\alpha$-keratins are present in the hair, wool, horns, nails, claws and hooves of mammals, while, $\beta$-keratins are present in nails, scales, claws of reptiles, shells, feathers, beaks of birds and quills ( $\mathrm{Ng}$ et al. 2012). The $\alpha$-keratins 
are the high molecular weight proteins $(\geq 40 \mathrm{kDa})$, while $\beta$-keratins have a low molecular weight of $\geq 10 \mathrm{kDa}$ (Fujii and Li 2008; Rouse and Van Dyke 2010; Alibardi et al. 2009; Toni and Alibardi 2007). Keratins have immense applications in pharmaceutical engineering, cosmetics, animal feedstock and fertilizer industry (Kumaran et al. 2016; Karthikeyan et al. 2007). These are insoluble macromolecules containing a tight packing of supercoiled long polypeptide chains. A high degree of cross-linked cystine between peptide chains in keratin imparts high stability and resistance to degradation. A wide number of techniques including reduction or oxidation reactions were employed to dissolve the hard keratin (Poole et al. 2011). Studies indicated that keratin from feathers can be extracted by breaking the disulfide bonds in the cystine (Anfinsen et al. 1961; Wrześniewska-Tosik and Adamiec 2007). Sodium sulfide $\left(\mathrm{Na}_{2} \mathrm{~S}\right)$ 2-mercaptoethanol and sodium dodecyl sulfate (SDS) were also used to obtain a good yield of keratin from various animal sources (Fan 2008; Karthikeyan et al. 2007; Sharma et al. 2016).

In this study, keratin was extracted from the chicken feather biomass and optimization of extraction conditions was carried out systematically. The extracted and purified keratin was characterized for its structural and biochemical properties. The aim of this research work was to screen the best reducing agent and optimize the extraction process using Design-Expert software. The effects of mass ratio of chicken feathers, solvent, extraction time, temperature of reaction, $\mathrm{pH}$ of solvent and concentration of solvent were analyzed.

\section{Materials and methods}

\section{Materials}

Fresh chicken feathers were supplied by a chicken processing plant at Jaya Gading, Kuantan, Malaysia. Sodium sulfide, sodium hydroxide, urea, sodium bisulfite, hydrochloric acid, sodium dodecyl sulfate (SDS), Tris(hydroxymethyl) aminomethane and 2-mercaptoethanol were purchased from Sigma-Aldrich (St. Louis, MO) USA. Precision Plus Protein ladder Kaleidoscope from BioRad with molecular weight range 10-200 kDa and protein ladder SeeBlue pre-stained standard (molecular weight range 3-188 $\mathrm{kDa}$ ) from Life Technologies were used as molecular weight markers. All other reagents were of analytical grade. The major instruments used were: UVvisible spectrophotometer, U-1800 Hitachi, UK; Fourier transform infrared spectroscopy, FTIR Thermo Scientific Nicolet iS5; size exclusion chromatography, AKTA Prime Plus from Amersham Biosciences; scanning electron microscope, EVO Series, from ZEISS, Germany.

\section{Screening of reducing agents}

\section{Pre-treatment and extraction of the feathers}

Chicken feathers were collected from chicken processing unit and washed to remove all the blood and dirt impurities. The feathers were then washed with detergent water and dried under sunlight. The dried feathers were then chopped into small pieces and ground. The ground feather biomass was collected in sealed plastic bags and stored for further use. The ground chicken feathers $(5 \mathrm{~g})$ were added to $200 \mathrm{ml}$ of reducing agent $\left(\mathrm{Na}_{2} \mathrm{~S} ; 0.5 \mathrm{M}\right)$. The solution was incubated at $60^{\circ} \mathrm{C}$ for $2 \mathrm{~h}$. The turbid solution was then filtered and separated by centrifugation at $10,000 \mathrm{rpm}$ for 5 min.

\section{Protein precipitation and purification}

The feather filtrate was taken in $250 \mathrm{ml}$ conical flask and $5 \mathrm{ml}$ of $\mathrm{HCl}(2 \mathrm{M})$ was added dropwise. The precipitates were separated by centrifugation at $10,000 \mathrm{rpm}$ and the sediment was washed with $\mathrm{ddH}_{2} \mathrm{O}$ three times. Then, the sediment was mixed with $30 \mathrm{ml}$ of $\mathrm{NaOH}(2 \mathrm{M})$ thoroughly and centrifuged again at 10,000 rpm for $5 \mathrm{~min}$. The supernatant was collected and stored for further experiments. The same procedure was repeated for the extraction of keratin using reducing agents in various compositions. The first reducing agent used was $\mathrm{Na}_{2} \mathrm{~S}(1 \mathrm{M})$. The second reducing agent used was $\mathrm{NaOH}(1 \mathrm{M})$. The third reducing agent contained a mixture of urea $(94.5 \mathrm{~g})$, SDS (15 g) and Tris(hydroxymethyl) aminomethane $(4.75 \mathrm{~g})$ in $23 \mathrm{ml}$ of 2-mercaptoethanol. The fourth reducing agent consisted of a mixture of SDS and sodium bisulfite (11:1 ratio) in $100 \mathrm{ml}$ of double distilled water $\left(\mathrm{ddH}_{2} \mathrm{O}\right)$. The last reducing agent was composed of a mixture of $\mathrm{NaOH}(1 \mathrm{M})$ and $\mathrm{Na}_{2} \mathrm{~S}(0.1 \mathrm{M})$. Among the tested reducing agents, the optimum yield was obtained with $1 \mathrm{M}, \mathrm{Na}_{2} \mathrm{~S}$. Protein concentration was determined by the Bradford method using bovine serum albumin (BSA) as a standard. All the experiments were carried out in triplicate and the mean average $( \pm \mathrm{SD})$ was calculated.

\section{Optimization of the extraction process}

The physico-chemical parameters including $\mathrm{pH}$, concentration of the reducing agent, incubation temperature, mass ratio of chicken feather to $\mathrm{Na}_{2} \mathrm{~S}$ and reaction time were optimized using Design-Expert software 7.0.0 (Stat-Ease, Inc., Minneapolis). Preliminary screening was done using a two-level factorial design. The temperature range (30$80{ }^{\circ} \mathrm{C}$ ) and incubation time from 1 to $12 \mathrm{~h}$ were selected. The concentration of the solvent used was $0.5-1 \mathrm{M}$, and the mass ratio of chicken feather to $\mathrm{Na}_{2} \mathrm{~S}(0.01-0.05 \mathrm{M})$ 
and $\mathrm{pH} 10-13$ were selected for the optimization. On the basis of results obtained from factorial design, response surface methodology (RSM) was first applied with the steepest ascent method, followed by the central composite design (CCD). The path of steepest ascent was applied to investigate the initial experimental region until there was no further increase in the response. The first-order model used to fit the results of the two-level design is represented by the equation:

$\hat{Y}=b_{0}+\sum_{i=1}^{k} b_{i} x_{i}$,

where $\hat{Y}$ is the predicted response, $b_{0}$ the intercept estimate, $k$ the number of design variables and $b_{i}$ the coefficient for factor $x_{i}$. After obtaining the model equation, one process variable was chosen as the base factor and the step size or increment $\left(\Delta x_{i}\right)$ was calculated for the base factor. Then, the increments in the other process variables were determined using the following equation:

$\Delta x_{j}=\frac{b_{j}}{b_{i}} \Delta x_{i}$

where $\Delta x_{j}$ is the increment of the design variable, $b_{j}$ the coefficient of the base factor, $b_{i}$ the coefficient of factor $x_{i}$ and $\Delta x_{i}$ the increment of the base factor. The increments were transformed from coded units to uncoded units according to the results in ANOVA from two-level factorial design analysis. From the steepest ascent method, the optimum point was allowed to become closer and a new design of experiment could be set up. The new region was applied in CCD to analyze the effects of the process parameters on the extraction of keratin and the optimum conditions for the experiment were directly determined. All experiments were run in triplicate and the results reported were the average value. Finally, the validation process was done by replicating the optimum run ten times.

\section{Characterization of keratin protein}

\section{Fourier transform infrared spectroscopy (FTIR)}

The chemical components of keratin were determined using FTIR spectroscopy to detect the presence of amide groups or protein. Thermo Scientific Nicolet iS5 FTIR was used for chemical characterization of treated and untreated CFs in between the 4000 and $700 \mathrm{~cm}^{-1}$ wave number range.

\section{Size exclusion chromatography (SEC)}

SEC of keratin protein was run with two protein standards and vitamin B12. Bovine serum albumin (BSA) and ovalbumin were used as the protein standard. The comparison of elution profiles of BSA, ovalbumin, vitamin B12 and protein sample was done.

Sodium dodecyl sulfate polyacrylamide gel electrophoresis (SDS-PAGE) analysis

To determine the molecular weight and purity, the keratin protein sample was analyzed by $10 \%$ SDS-PAGE. Coomassie Brilliant Blue staining method and silver staining method were used to stain the gel.

Amino acid profile analysis and scanning electron microscopy (SEM)

The composition of amino acids in the keratin obtained was analyzed using HPLC. The surface properties and morphology of the lyophilized samples of keratin were studied using SEM imaging.

\section{Results and discussion}

\section{Screening of reducing agents}

Among the five reducing agents used, $\mathrm{Na}_{2} \mathrm{~S}$ showed $86.5 \%$ protein extraction as compared to the urea mixture (50.6\%), $\mathrm{NaOH}(43.8 \%)$, mixture of $\mathrm{Na}_{2} \mathrm{~S}$ and $\mathrm{NaOH}$ (41.5\%) and $\sim 18.3 \%$ bisulfite mixture as shown in Fig. 1. Therefore, $\mathrm{Na}_{2} \mathrm{~S}$ was selected to extract keratin protein from chicken feather. The model of experiment, temperature $\left(X_{1}\right)$, time $\left(X_{2}\right)$, ratio of $\mathrm{CF}: \mathrm{Na}_{2} \mathrm{~S}\left(X_{4}\right)$ and concentration $\left(X_{5}\right)$ were significant model terms. $\mathrm{pH}\left(X_{3}\right)$ was not significant due to $p>0.10$. $\mathrm{pH}$ values higher than $7-10$ were preferably used in previous studies (Floris and Slangen 2005) and thus pH 10 was used. Sulfide dissociation of equilibrium shift toward $\mathrm{S}^{2-}$, which is stronger than $\mathrm{HS}^{-}$

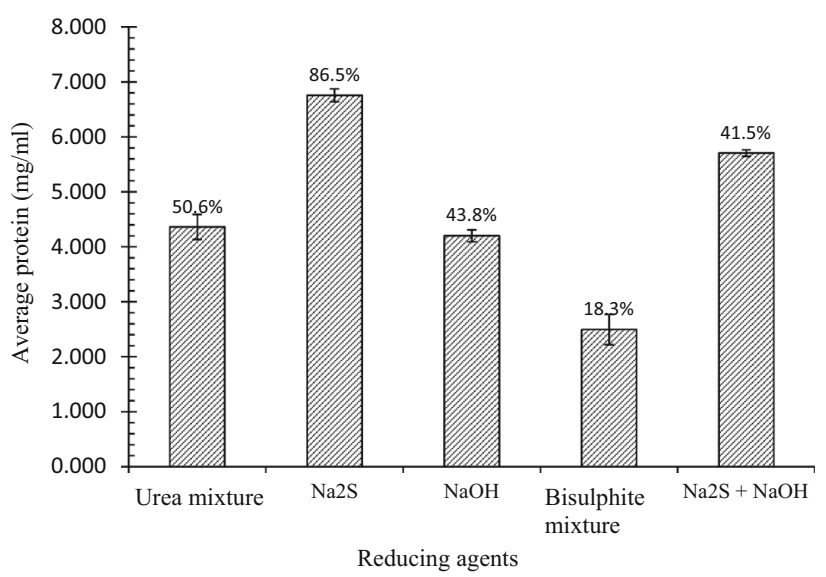

Fig. 1 Effect of different reducing agents on keratin extraction 
reductor as reported previously (Poole et al. 2011). The mass of keratin protein had no significant effect when $\mathrm{pH}$ was varied from 10 to 13 .

The model of experiment was significant with $p<0.05$ and adj $R^{2}=0.9996$. In this model, the curvature was not significant, which indicated that the design was not close to the optimum response. The optimal point is outside the experimental design space and the method of steepest ascent should be applied. The corresponding first-order model equation was fitted to the data obtained from the factorial design experiment using equation:

$$
\begin{aligned}
\hat{Y}= & 2.49+0.52 x_{1}+0.63 x_{2}+0.017 x_{3}+0.24 x_{4} \\
& +0.16 x_{5},
\end{aligned}
$$

where $x_{1}$ is the temperature, $x_{2}$ the time, $x_{3}$ the $\mathrm{pH}, \mathrm{x}_{4}$ the ratio of mass of chicken feather to $\mathrm{Na}_{2} \mathrm{~S}\left(\mathrm{CF}: \mathrm{Na}_{2} \mathrm{~S}\right)$ and $\mathrm{x}_{5}$ the concentration of $\mathrm{Na}_{2} \mathrm{~S}$.

\section{Steepest ascent path}

The direction of the steepest ascent path was determined by Eq. (3) and regression results. From the first-order model Eq. (3), it was predicted that the protein yield increased with increase in the selected factors. The center point of the fractional factorial design was considered as the origin of the path. Time was chosen as the base factor. The path of the steepest ascent showed a maximum $4.03 \mathrm{~g}$ of protein at run 4. Consequently, an optimum region had been found and this point was used for further optimization.

\section{Central composite design}

The conditions at the fourth run were chosen as center point in the central composite design. The ANOVA results in the two-level factorial showed a $p$ value of 0.424 for $\mathrm{pH}$, which is insignificant. Therefore, the new conditions for center point in CCD was temperature of extraction $\left(x_{1}=77.51{ }^{\circ} \mathrm{C}\right)$, incubation time $\left(x_{2}=12.5 \mathrm{~h}\right)$, ratio of $\left(\mathrm{CF}: \mathrm{Na}_{2} \mathrm{~S}\right) \quad\left(x_{3}=0.38\right)$ and concentration of $\mathrm{Na}_{2} \mathrm{~S}$ $\left(x_{4}=0.82 \mathrm{M}\right)$.
The statistical significance of the model equation was checked by an $F$ test (ANOVA). The $F$ test suggested that the model had a very high $F$ value $(F=322.34)$, indicating that this model was highly significant. The mass of protein gained was affected significantly by the extraction temperature $\left(X_{1}\right)$, extraction time $\left(X_{2}\right)$ and concentration of $\mathrm{Na}_{2} \mathrm{~S}\left(X_{3}\right)$ with $p<0.0001$, while the ratio of mass $\mathrm{CF}: \mathrm{Na}_{2} \mathrm{~S}\left(X_{4}\right)$ was not significant with $p>0.1$. The anal$y$ ysis of variance (ANOVA) of mass of keratin protein gained indicated that experimental data had a determination coefficient $\left(R^{2}=0.9967\right)$. The calculated model was able to explain $99.67 \%$ of the results. $R^{2}$ adj value (adjusted determination coefficient) is the correlation measure for testing the goodness of fit of the regression equation. $R^{2}$ adj value of this model was 0.9963 , which indicated only $0.37 \%$ of the total variations. The lack of fit $F$ value of 2.17 implies that the lack of fit is not significant relative to the pure error. The $p$ value showed that the lack of fit was 0.20 , which indicated that the model appeared to be appropriate for the optimal region. The normal plot of residuals is shown in Fig. 1. A linear pattern demonstrated normality in the error term.

The predicted model was further assessed by RSM analysis. The $3 \mathrm{D}$ plot provides a means to visualize interactions between the variables and to rapidly estimate the optimum level of each variable for maximum response. The ANOVA for the RSM is given in Table 1. The resulting response surfaces in Fig. 2 show the effect of temperature of medium extraction, concentration of $\mathrm{Na}_{2} \mathrm{~S}$ solvent, incubation time and ratio of mass of chicken feather on the mass of keratin protein extracted. Each figure addresses the combined effects of two variables, while the remaining variables are maintained at a constant level.

Figure 2a, b showed the interaction between reaction temperature $\left(X_{1}\right)$ and time $\left(X_{2}\right)$ with respect to the mass of protein gained. Increase in the extraction temperature from 67.5 to $77.5^{\circ} \mathrm{C}$ with time from 9.5 to $15.5 \mathrm{~h}$ enhanced the mass of protein gained. However, with increase of reaction temperature over $77.5^{\circ} \mathrm{C}$, a gradual decrease in the response was recorded. Thus, above $77.5^{\circ} \mathrm{C}$, it denatures the protein and decreases the total yield. Extraction

Table 1 ANOVA for response surface quadratic model

\begin{tabular}{lcclrlr}
\hline Source & Sum of squares & $d f$ & Mean square & $F$ value & $p>F$ & Significant \\
\hline Model & 14.91 & 15 & 0.99 & 301.09 & 0.0033 & 0.0009 \\
$X_{1}$-temperature & 0.071 & 1 & 3.77 & 1142.91 & 0.0006 & Not significant \\
$X_{2}$-time & 0.058 & 1 & 5.77 & 1746.77 & 0.99 & 0.4241 \\
$X_{3}-\mathrm{pH}$ & 0.013 & 1 & $3.278 \mathrm{E}-3$ & 209.74 & 0.0047 \\
$X_{4}-\mathrm{CF}: \mathrm{Na}_{2} \mathrm{~S}$ & & 1 & 0.69 & 83.38 & 0.0118 & 0.2835 \\
$X_{5}$-concentration & & 1 & 0.28 & 2.11 & \\
Curvature & $6.969 \mathrm{E}-3$ & 1 & $6.969 \mathrm{E}-3$ & &
\end{tabular}


A

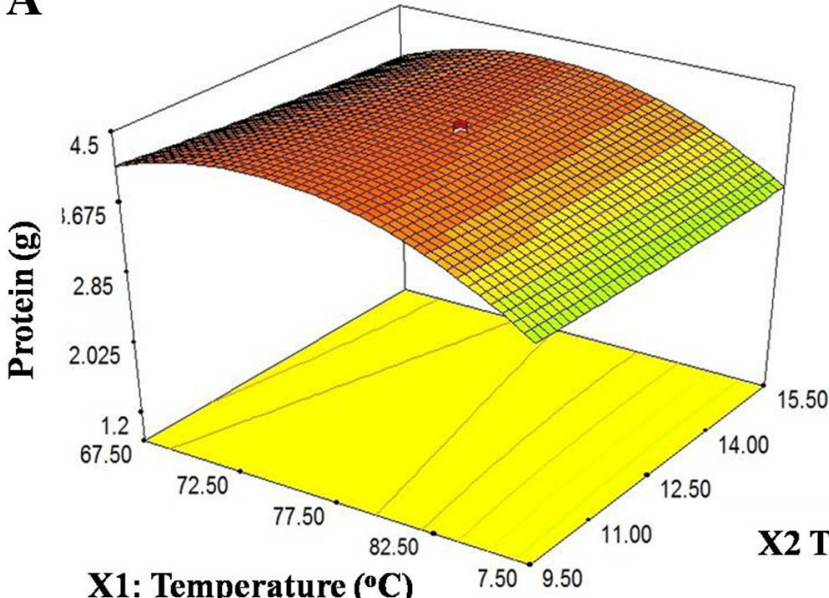

$\mathrm{X} 1$ : Temperature $\left({ }^{\circ} \mathrm{C}\right)$

C

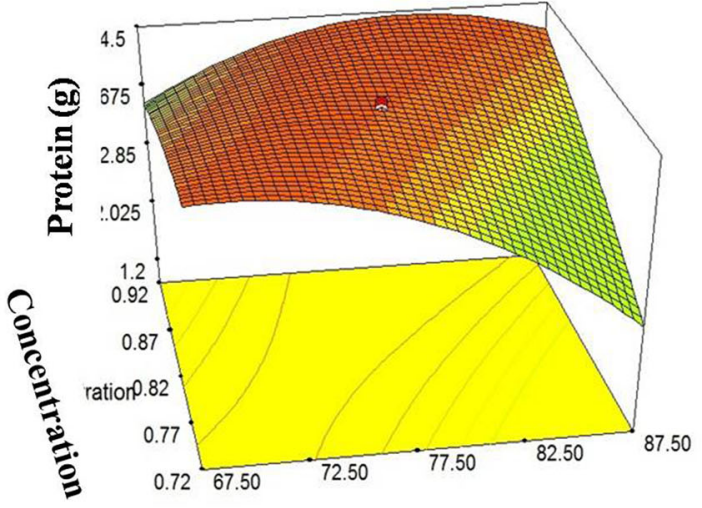

$\mathrm{X} 1$ : Temperature $\left({ }^{\circ} \mathrm{C}\right)$

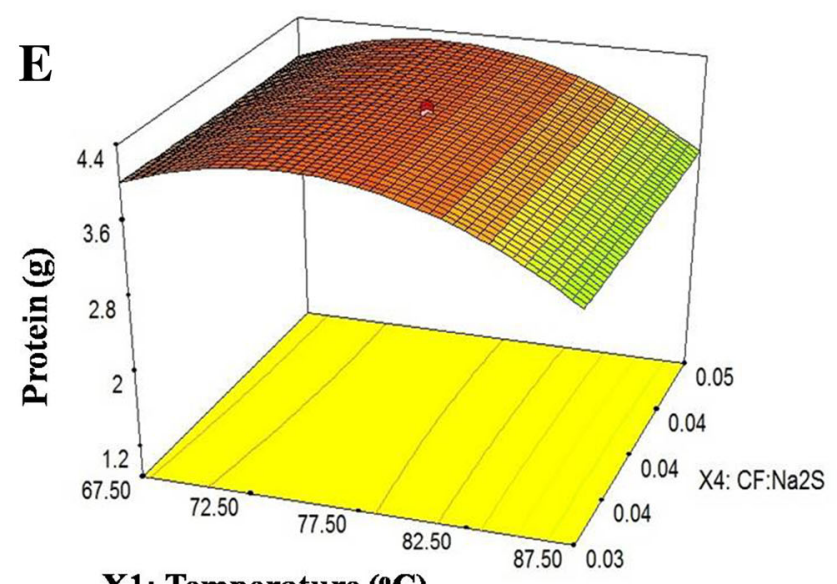

$\mathrm{X} 1$ : Temperature $\left({ }^{\circ} \mathrm{C}\right)$

Fig. 2 Response surface curves of temperature $\left(X_{1}\right)$ vs. time $\left(X_{2}\right)$ for mass of protein $(\mathrm{g})$ extracted from chicken feathers. a Threedimensional surface plot and $\mathbf{b}$ contour map. c Three-dimensional surface plot of temperature $\left(X_{1}\right)$ vs. concentration of $\mathrm{Na}_{2} \mathrm{~S}\left(X_{3}\right)$ for the
B

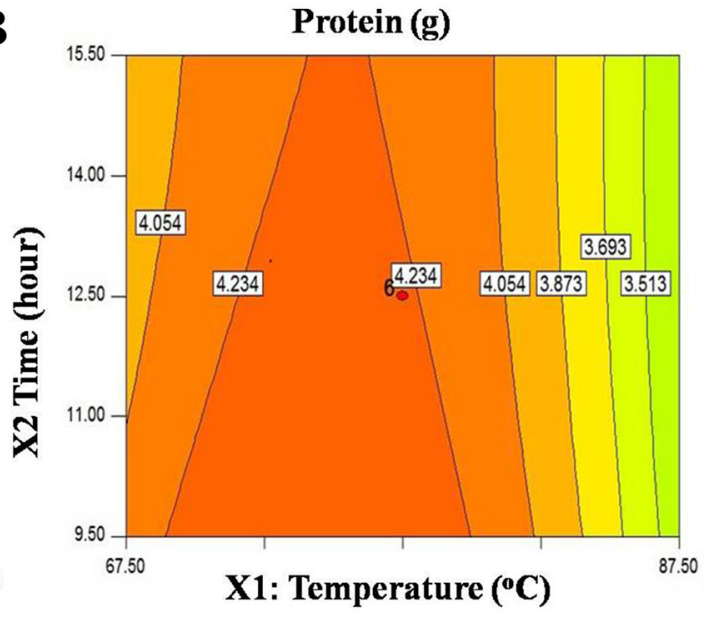

Protein (g)
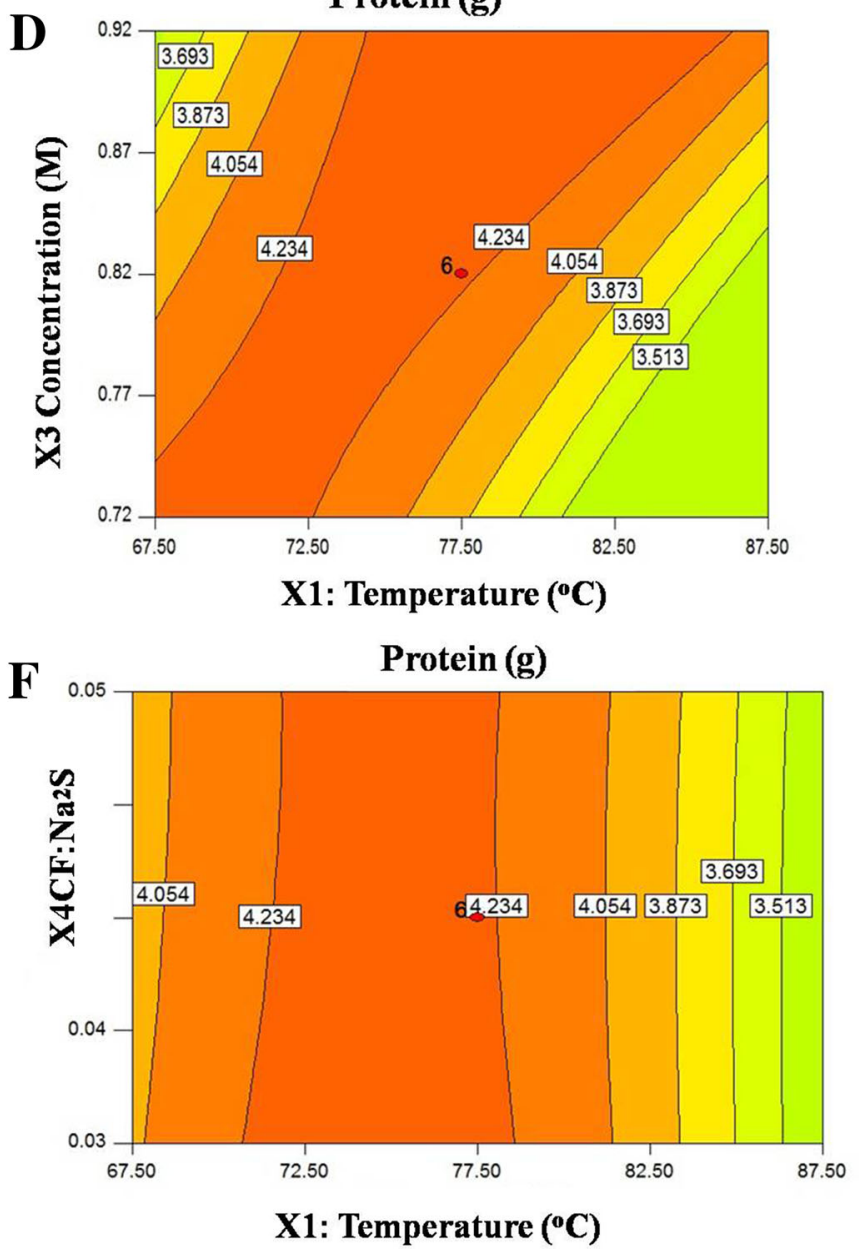

mass of protein $(\mathrm{g})$ and $\mathbf{d}$ contour map. e Three-dimensional surface plot of temperature $\left(X_{1}\right)$ vs. ratio of $\mathrm{CF}: \mathrm{Na}_{2} \mathrm{~S}\left(X_{4}\right)$ for the mass of protein $(\mathrm{g})$ and $\mathbf{f}$ contour map 
Fig. 3 FTIR spectra of keratin extracted by $\mathrm{Na}_{2} \mathrm{~S}$ (a before and b after dialysis)
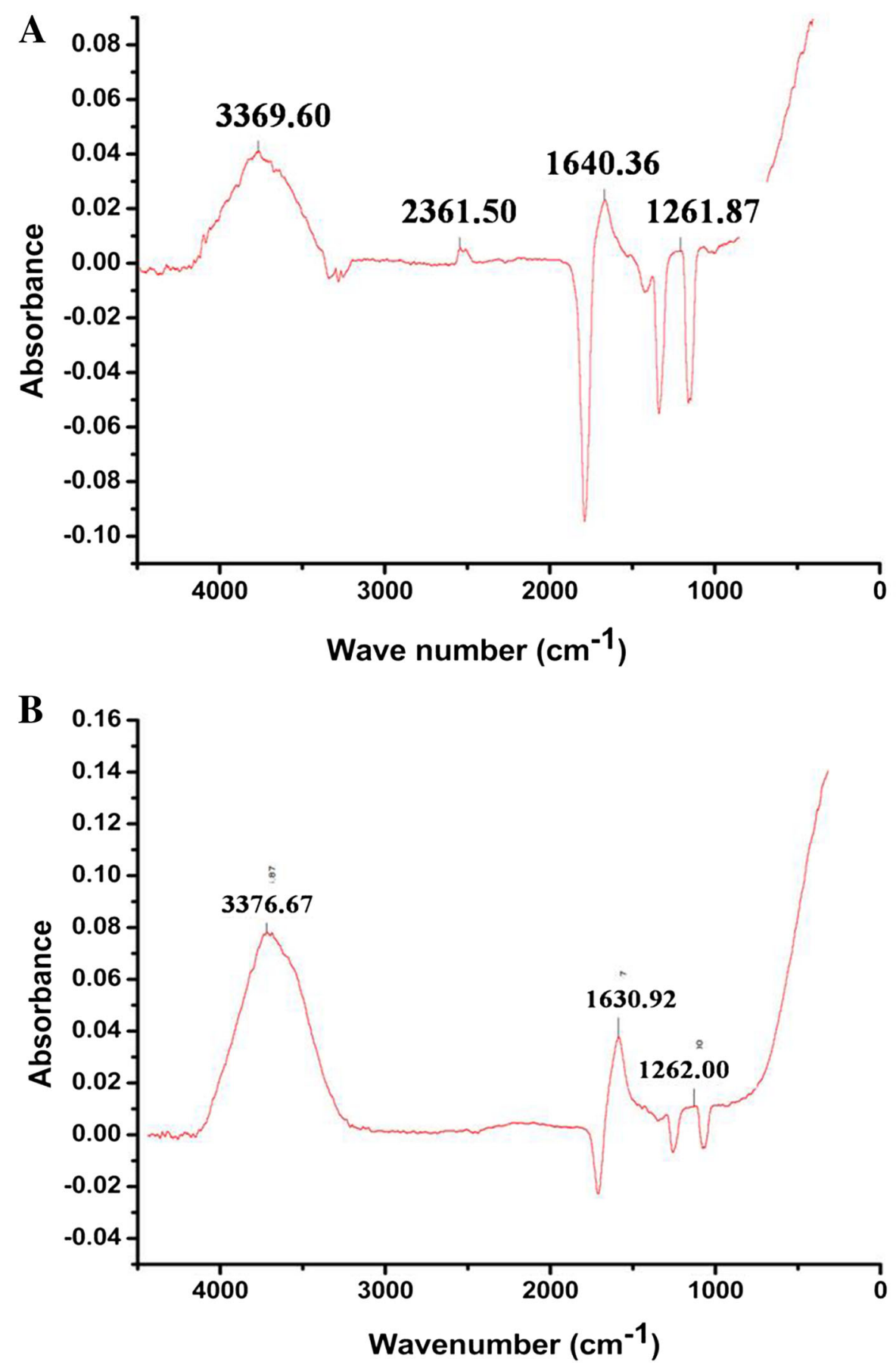

temperature showed significant effect on the mass of protein extracted (Floris and Slangen 2005); keratins can also be extracted at low temperature $\left(20^{\circ} \mathrm{C}\right)$; however, preferably they are extracted at high temperature $\left(50-80{ }^{\circ} \mathrm{C}\right)$.

The effect of a combination of extraction temperature $\left(X_{1}\right)$ and concentration of $\mathrm{Na}_{2} \mathrm{~S}\left(X_{3}\right)$ on the mass of protein obtained is shown in Fig. 2c, d. With increase in the concentration of $\mathrm{Na}_{2} \mathrm{~S}$ from 0.72 to $0.92 \mathrm{M}$, the mass of protein obtained increased gradually at $77.5^{\circ} \mathrm{C}$. Further increase in the concentration of $\mathrm{Na}_{2} \mathrm{~S}$ results in decrease of the total yield. Thus, the concentration of the extraction medium is an important parameter; as the concentration increased, the disulfide bonds decreased (Saucedo-Rivalcoba et al. 2011).

As shown in Fig. 2e, f, the interaction of extraction temperature $\left(X_{1}\right)$ and the ratio of mass $\mathrm{CF}: \mathrm{Na}_{2} \mathrm{~S}\left(X_{4}\right)$ did not have much effect on the mass of protein gained ( $p=0.2343)$. The maximum mass of protein gain could be achieved at an extraction temperature of 77.5. The software predicted that the optimum extraction temperature, extraction time, 
Fig. 4 SDS-PAGE of keratin protein at different stages of purification a with protein marker and S1 (8 and 7), S2 (6), S3 (6 and 7), P, b with Precision Plus Protein standard

Kaleidoscope by silver staining (S1 precipitated protein which underwent SEC, $S 2$ precipitated protein which underwent dialysis and SEC, $S 3$ crude protein that underwent SEC, $P$ precipitated concentrate protein that underwent SEC)

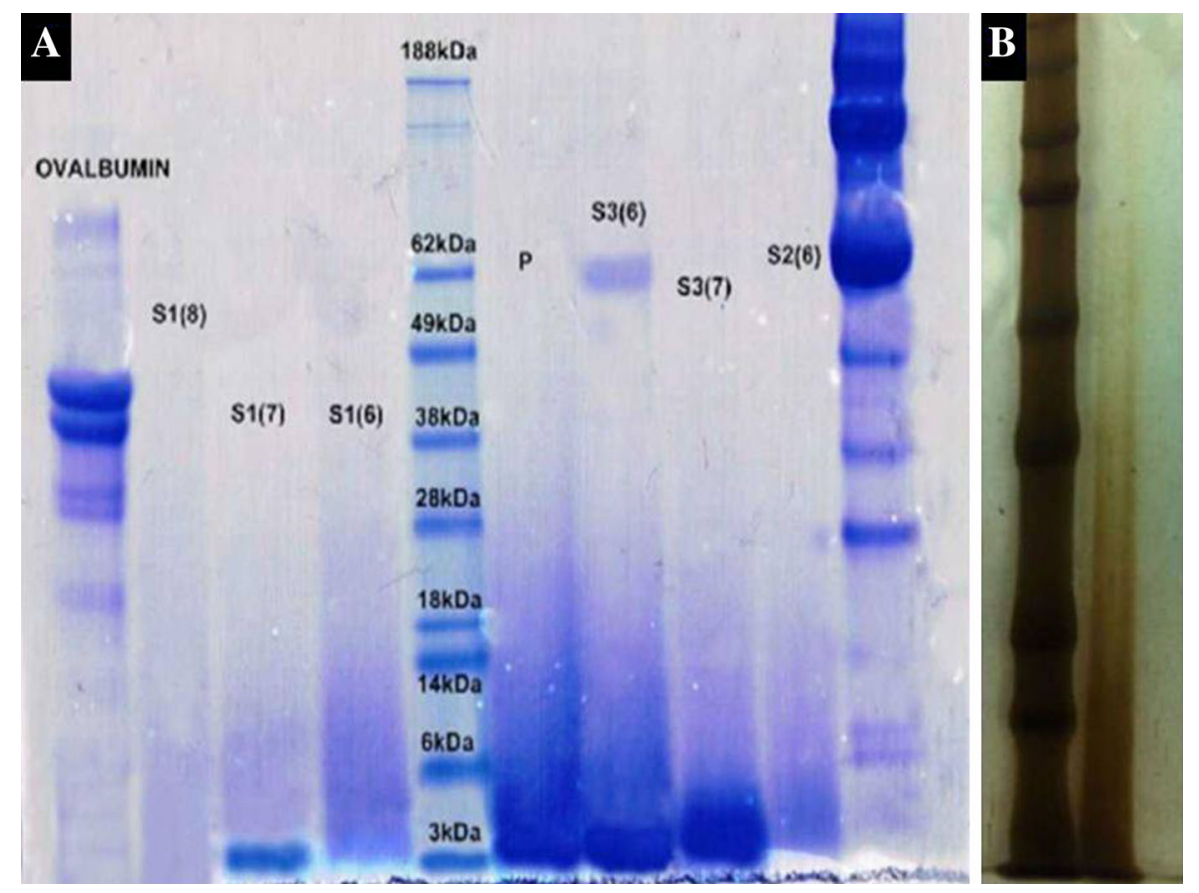

Table 2 The percentage of amino acid in the extracted keratin

\begin{tabular}{lc}
\hline Amino acid & Content $(\%)$ \\
\hline Aspartic acid & 7.59 \\
Serine & 12.28 \\
Glycine & 0.003 \\
Glutamic acid & 12.41 \\
Histidine & 9.08 \\
Arginine & 1.08 \\
Threonine & 2.19 \\
Alanine & 3.82 \\
Proline & 11.47 \\
Tyrosine & 1.42 \\
Valine & 6.79 \\
Lysine & 3.32 \\
Isoleucine & 5.88 \\
Leucine & 8.85 \\
Phenylalanine & 5.34 \\
Cysteine & 6.83 \\
Methionine & 1.66 \\
\hline
\end{tabular}

concentration and ratio of mass CF: $\mathrm{Na}_{2} \mathrm{~S}$ were $80.9{ }^{\circ} \mathrm{C}$, $9.5 \mathrm{~h}, 0.92 \mathrm{M}$ and 0.05 , respectively. The software predicted that the mass of protein gained was $4.56 \mathrm{~g}$. A total of ten parallel experiments were carried out under the optimal conditions. The results from ten replicates were consistent with the predicted values; thus, the model was proved to be adequate. Compared with the predicted values by RSM, the percentage error was $0.10 \%$. The mass of keratin protein obtained from optimization increased by $5.29 \%$ from the original condition; from 86.5 to $91.1 \%$ protein can be extracted out of $5 \mathrm{~g}$ of feather biomass.

\section{Characterization of extracted keratin}

\section{Fourier transform infrared spectroscopy (FTIR)}

FTIR spectra of keratin protein are shown in Fig. 3. It represented the carboxylic acids groups in the sample at wave numbers 1261 and $1262 \mathrm{~cm}^{-1}$ (Fig. 3). The bands at 3369 and $3376 \mathrm{~cm}^{-1}$ correspond to the amide group, while the absorption at wave number $2361 \mathrm{~cm}^{-1}$ was attributed to the amine group (Fig. 3a). Thus, FTIR confirmed the presence of amino acids such as cystine, glutamine and threonine in the protein sample.

\section{Size exclusion chromatography (SEC)}

In the chromatographic separation the BSA molecule eluted first followed by ovalbumin, keratin protein and finally vitamin B12 which is of smallest size. The molecular weight of BSA, ovalbumin and vitamin B12 is 66.5, 44.3 and $1.36 \mathrm{kDa}$, respectively. The molecular weight of the sample protein was estimated between 1.36 and $44.3 \mathrm{kDa}$.

\section{SDS-PAGE analysis}

Coomassie Brilliant Blue staining method and silver staining method were used to stain the gel (Fig. 4). Further, it showed the presence of keratin proteins at four stages of purification, S1, S2, S3, and P, with molecular weight 3 and 

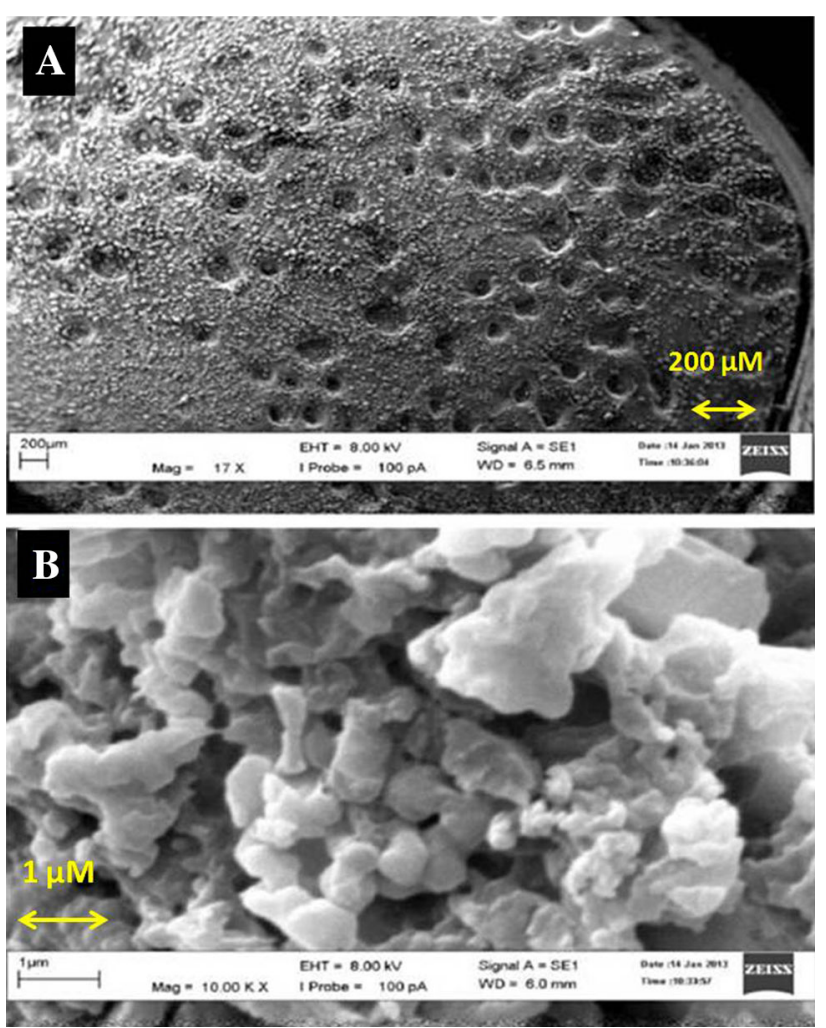

Fig. 5 Scanning electron microscopic images of keratin $\mathbf{a} \times 17$ magnification, $\mathbf{b} \times 10,000$ magnification

6, $62 \mathrm{kDa}$, and 3-14 kDa respectively. According to (Floris and Slangen 2005), keratin protein basically has molecular weight of between 1 and $11 \mathrm{kDa}$; and in typically in between 3 and $10.4 \mathrm{kDa}$. Our results showed two types of keratin proteins with low molecular weight $3 \mathrm{kDa}$ and high molecular weight $62 \mathrm{kDa}$.

\section{Amino acid profile and SEM analysis}

The production of amino acids in keratin was investigated using HPLC. The amino acid compositions were measured in $50 \mathrm{ml}$ keratin solution, containing $2.5 \mathrm{~g}$ of chicken feathers. The percentage of all amino acids present is given in Table 2 . This study showed that cystine is about $6.83 \%$, which is similar to a previous study that showed the cystine in keratin samples. The keratin obtained was clearly visible under microscopic observation in powder form. SEM images showed that keratin appeared like small particles in dust form or aggregates (Fig. 5a, b) when magnified to $\times 10,000$.

\section{Conclusion}

In conclusion, the statistical optimization of keratin extraction from chicken feather using Design-Expert concomitantly increased the yield from 86.5 to $91 \%$. The keratin yield was remarkably increased by $\mathrm{Na}_{2} \mathrm{~S}$ using a central composite design. The optimum point for the extraction process was predicted and the validation of the optimum condition was done. The optimum temperature for extraction of keratin was $80.9^{\circ} \mathrm{C}$ in $9.5 \mathrm{~h}$, with $\mathrm{Na}_{2} \mathrm{~S}$ $(0.92 \mathrm{M})$, and the ratio of mass of chicken feathers to $\mathrm{Na}_{2} \mathrm{~S}$ 0.05 . Finally, the statistical optimization of extraction condition provided better understanding of the reaction parameters with a good yield of keratin. The extraction process of keratin can be scaled up from the laboratory to the industrial level.

Acknowledgements The authors are thankful to University Malaysia Pahang (UMP) for providing facilities and financial support. Author NK is thankful to UMP for providing Graduate Research Scheme (GRS) scholarship as financial support. Author SS is thankful to UMP for providing Doctoral Scholarship Scheme (DSS) as financial support.

\section{Compliance with ethical standards}

Conflict of interest The authors declare that there is no conflict of interest.

\section{References}

Alibardi L, Dalla Valle L, Nardi A, Toni M (2009) Evolution of hard proteins in the sauropsid integument in relation to the cornification of skin derivatives in amniotes. J Anat 214(4):560-586

Anfinsen CB, Haber E, Sela M, White F (1961) The kinetics of formation of native ribonuclease during oxidation of the reduced polypeptide chain. Proc Natl Acad Sci 47(9):1309-1314

Barone JR, Schmidt WF, Gregoire N (2006) Extrusion of feather keratin. J Appl Polym Sci 100(2):1432-1442

Fakhfakh-Zouari N, Haddar A, Hmidet N, Frikha F, Nasri M (2010) Application of statistical experimental design for optimization of keratinases production by Bacillus pumilus $\mathrm{A} 1$ grown on chicken feather and some biochemical properties. Process Biochem 45(5):617-626

Fan X (2008) Value-added products from chicken feather fiber and protein. Dissertation, Auburn University

Floris TA, Slangen K (2005) Method for producing a low reducing agent-containing keratin and products thereof. U.S. Patent Application No. 11/791,739

Fujii T, Li D (2008) Preparation and properties of protein films and particles from chicken feather. J Biomacromolecules 8:48-55

Gessesse A, Hatti-Kaul R, Gashe BA, Mattiasson B (2003) Novel alkaline proteases from alkaliphilic bacteria grown on chicken feather. Enzym Microbial Technol 32(5):519-524

Grazziotin A, Pimentel F, De Jong E, Brandelli A (2006) Nutritional improvement of feather protein by treatment with microbial keratinase. Anim Feed Sci Technol 126(1):135-144

Karthikeyan R, Balaji S, Sehgal P (2007) Industrial applications of keratins-a review. J Sci Ind Res 66(9):710

Kumaran P, Gupta A, Sharma S (2016) Synthesis of wound-healing keratin hydrogels using chicken feathers proteins and its properties. doi:10.22159/ijpps.2017v9i2.15620

Ng CS, Wu P, Foley J, Foley A, McDonald M-L, Juan W-T, Huang C-J, Lai Y-T, Lo W-S, Chen C-F (2012) The chicken frizzle feather is due to an $\alpha$-keratin (KRT75) mutation that causes a defective rachis. PLoS Genet 8(7):e1002748 
Poole AJ, Lyons RE, Church JS (2011) Dissolving feather keratin using sodium sulfide for bio-polymer applications. J Polym Environ 19(4):995-1004

Rouse JG, Van Dyke ME (2010) A review of keratin-based biomaterials for biomedical applications. Materials 3(2):999-1014

Saucedo-Rivalcoba V, Martínez-Hernández A, Martínez-Barrera G, Velasco-Santos C, Castaño V (2011) (Chicken feathers keratin)/ polyurethane membranes. Appl Phys A 104(1):219-228

Sharma S, Gupta A (2016) Sustainable management of keratin waste biomass: applications and future perspectives. Braz Arch Biol Technol 59:e16150684. doi:10.1590/1678-4324-2016150684
Sharma S, Gupta A, Chik SMST, Gek KC, Podde PK, Thraisingam J, Subramaniam M (2016) Extraction and characterization of keratin from chicken feather waste biomass: a study. In: Proceedings of the national conference for postgraduate research (NCON-PGR 2016), Universiti Malaysia Pahang (UMP), Pekan, pp 693-699, 24-25 Sept 2016

Toni M, Alibardi L (2007) Alpha-and beta-keratins of the snake epidermis. Zoology 110(1):41-47

Wrześniewska-Tosik K, Adamiec J (2007) Biocomposites with a content of keratin from chicken feathers. Fibres Text East Eur 15(1):60 